\title{
Abnormal left ventricular wall movement in patients with chest pain and normal coronary arteriograms Relation to inferior $T$ wave changes and mitral prolapse
}

\author{
D. G. GIBSON AND D. J. BROWN \\ From the Cardiac Department, Brompton Hospital, London
}

SUMMARY Left ventriculograms of 45 patients with angina and normal coronary arteriograms were digitised frame by frame in order to detect regional abnormalities of wall movement. Though left ventricular pressures, end-diastolic volume, and ejection fraction were normal in all, regional outward movement during early systole was present in 10 patients, and abnormal inward wall movement during isovolumic relaxation also in 10, involving the apex or inferior surface. Both were present together in 8 patients, and affected segments showed normal amplitude and peak velocity of movement during ejection. These disturbances of wall movement were associated with inferior $T$ wave changes on the electrocardiogram, and mitral prolapse, particularly when the latter resulted from delayed movement of the valve during ejection. It is suggested that the onset of contraction is delayed in affected areas, but that it proceeds normally thereafter. The resulting persistence of tension into the period of relaxation of the remainder of the ventricle may interfere locally with coronary flow, particularly during tachycardia, thus causing manifestations of regional ischaemia.

The syndrome of chest pain with normal coronary arteries is an intriguing clinical entity (Kemp et al., 1967 ; Likoff et al., 1967) since many of the features of coronary artery disease, including acute myocardial infarction, electrocardiographic abnormalities, functional mitral regurgitation, and ventricular arrhythmias may occur in the presence of normal coronary artery anatomy. Its existence demonstrates a basic lack of knowledge of the mechanisms underlying these manifestations of coronary artery disease. In a previous angiographic investigation of patients with hypertrophic cardiomyopathy (Sanderson et al., 1977), it was observed that angina in this condition was associated with abnormal left ventricular relaxation. It was the purpose of the present study to examine the left ventriculograms of patients with chest pain and normal coronary arteries in greater detail than previously, in order to see if similar abnormalities were present.

\section{Methods}

Forty-five patients were studied, with normal left ventricular pressures, volumes, and coronary arteriograms. All had been referred for cardiac

Received for publication 30 May 1978 catheterisation on account of chest pain suspected to be caused by ischaemic heart disease. In 40 , the pain was intermittent and recurrent, and was thought to represent angina pectoris. In the remaining 5 , together with 5 in the preceding group, there was a history of one or more prolonged episodes of chest pain simulating that of acute myocardial infarction. In no patient was there positive electrocardiographic evidence of Prinzmetal angina.

In the history, the following features were noted: (1) the site; (2) the nature of the pain; (3) its relation to exercise or emotion; and (4) the effect of glyceryl trinitrate. These features were scored as positive $(+1)$ if they were typical of angina pectoris, and zero if they were not. The physical findings were reviewed with special reference to third or fourth heart sounds, or systolic murmurs, particularly those suggestive of mitral regurgitation. On the electrocardiogram, the mean $Q R S$ and $T$ vectors were measured, and the QRS-T angle derived. Any additional significant cardiographic abnormalities were noted.

Left ventriculograms were performed as previously described (Gibson et al., 1976), followed by selective coronary arteriography. In all studies, the first contrast injection, apart from small test doses, 

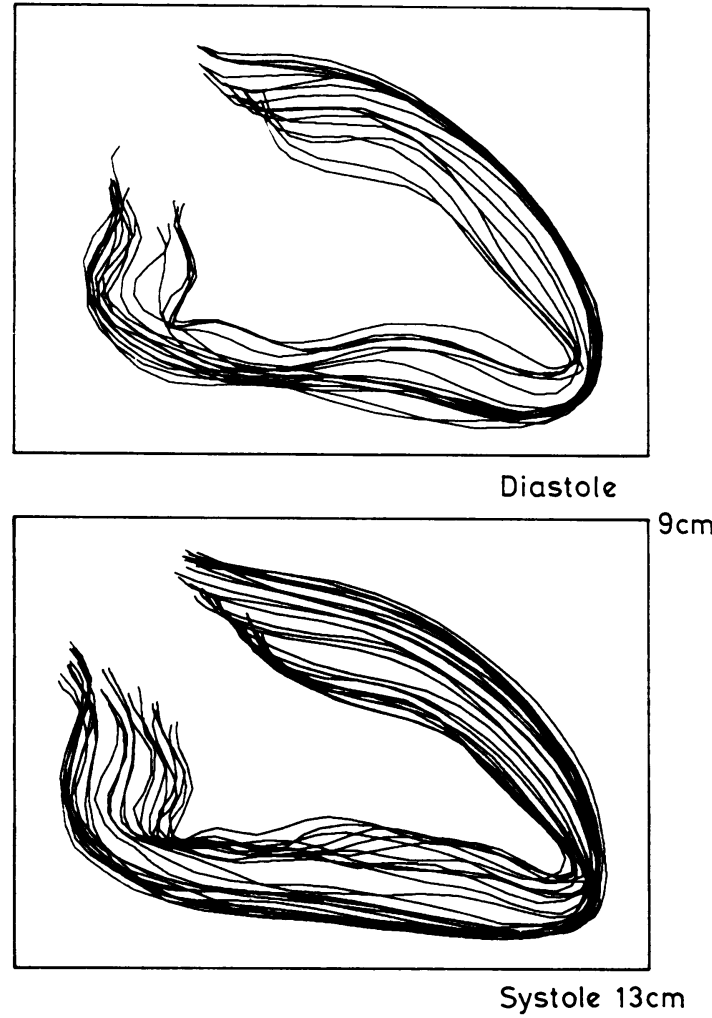

Fig. 1 Superimposed cavity outlines from a patient with a normal coronary arteriogram showing mitral prolapse. The outlines from the start of the beat to that with the smallest area are labelled 'systole' and the remainder 'diastole'.

was used for the left ventriculogram. Pressures were measured before angiography with fluid filled manometers, and were referred to the level of the mid-thorax. Left ventriculograms were digitised frame by frame (Gibson et al., 1976), using a Summagraphics digitiser and a Prime 300 computer system. From digitised data, the following information was extracted.

(1) End-diastolic volume and ejection fraction.

(2) Plots of superimposed cavity outlines (Fig. 1). From these plots, regions where the overall amplitude of wall movement was reduced could be identified. In addition, an assessment of the presence or absence of mitral valve prolapse was made. The term 'prolapse' is to some extent a misnomer, since in many cases the valve did not move outward from its end-diastolic position, rather it failed to move inwards normally with the base of the heart during early and mid-ejection, and this was associated with a pronounced increase in local

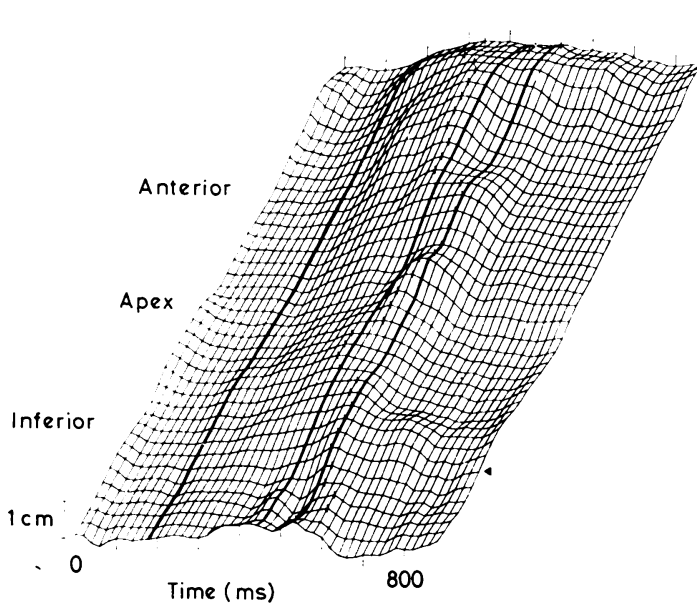

Fig. 2 Isometric plot of a left ventriculogram, showing abnormal wall movement at the apex, where there is outward movement during early systole, and inward movement during isovolumic relaxation. The three accentuated time lines represent the onset of aortic valve opening, minimum cavity area, and the onset of mitral valve opening. The plot marked with an arrow in the inferior region represents movement of the mitral valve.

curvature. This sequence of events on the digitised cavity outlines was readily recognisable to a radiologist as mitral prolapse on the original angiogram (Aranda et al., 1975; Smith et al., 1977).

(3) Isometric plots of regional wall movement were prepared (Gibson et al., 1976) (Fig. 2). The timing of the cine frames showing the start of aortic valve opening and of mitral valve opening were superimposed, along with that of the minimum cavity area. From these plots, abnormalities of wall movement during the two isovolumic periods were identified and localised.

(4) Specific plots from abnormal regions of endocardial position and its rate of change with time were made so that abnormal wall movement could be analysed in greater detail (Gibson et al., 1976). These were compared with similar plots from normal regions of the same ventricle (Fig. 2). Measurements were made of overall amplitude of movement, of any outward movement before, or immediately after the start of aortic valve opening, of inward or outward movement during the interval between minimum cavity area and mitral valve opening, and, finally, of the peak rate of inward movement during ejection.

A series of similar plots showing movement in the region of the mitral valve was prepared (see Fig. 4) in order to define the events of mitral valve prolapse in more detail. From these records, measurements 


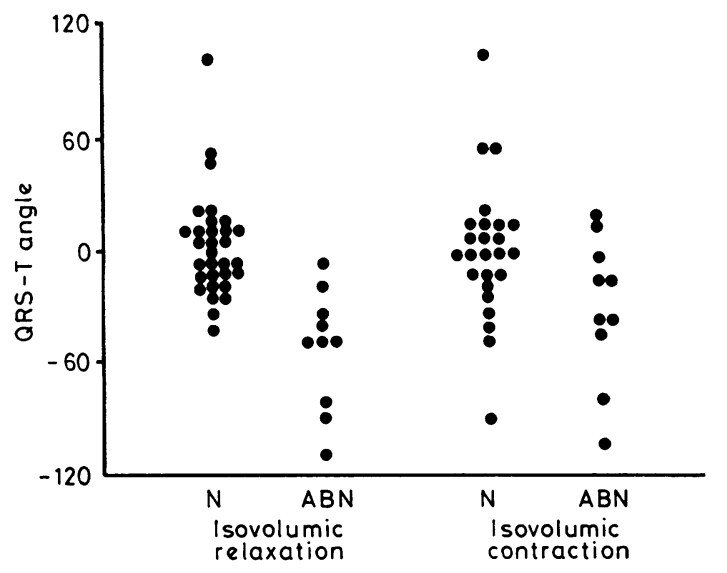

Fig. 3 Relation between $Q R S-T$ angle and abnormal left ventricular wall movement during isovolumic contraction and relaxation.

were made of: (a) overall amplitude of movement of the valve; (b) any outward movement (that is towards the left atrium) between the times of aortic valve opening and maximum cavity area; (c) the amplitude of inward movement between the times of minimum cavity area and mitral valve opening, expressed in absolute terms and also as a percentage of total movement.

Statistical analysis was by t tests, Fisher's exact probability tests, or $\chi^{2}$ tests, as appropriate.

\section{Results}

\section{CLINICAL}

In only 5 patients were all the characteristics of angina pectoris present, and in 14 there were none (Table 1). On physical examination, a soft systolic murmur was present in 6 , though none had a midsystolic click or late systolic murmur. The latter finding reflects our belief that cardiac catheterisation is not necessary to diagnose this entity, and to this extent the series of patients studied was a selected one. No patient had clinical evidence of left ventricular disease, though 2 , with left bundlebranch block, had reversed splitting of the second heart sound.

\section{Table 1 History of chest pain}

\begin{tabular}{lrl}
\hline No features of angina pectoris & 14 & $(0)$ \\
1 feature of angina pectoris & 6 & $(1)$ \\
2 features of angina pectoris & 12 & $(5)$ \\
3 features of angina pectoris & 8 & $(2)$ \\
4 features of angina pectoris & 5 & $(2)$ \\
\hline
\end{tabular}

Figures in parentheses indicate patients with history of prolonged chest pain simulating myocardial infarction.
Chest $x$-ray showed a normal sized heart in all cases.

\section{ELECTROCARDIOGRAM}

The electrocardiogram was abnormal in 16 patients: inferior $\mathrm{T}$ wave inversion, 10; left bundle-branch block, 2; left anterior hemiblock, 2; $\mathrm{T}$ wave inversion $V 1$ to $V 5,1$; and generalised $T$ wave flattening, 1.

No patient had significant $Q$ waves, and all were in sinus rhythm.

\section{HAEMODYNAMICS}

Left ventricular end-diastolic pressure was less than $12 \mathrm{mmHg}$ in 31 patients, and between 12 and $15 \mathrm{mmHg}$ in 14 .

\section{ANGIOGRAPHY}

Left ventricular end-diastolic volume was less than $140 \mathrm{ml}$ in all cases, and ejection fraction was in the range 63 to 88 per cent. Significant mitral prolapse was present on inspection of the angiograms in 16 patients. Abnormal outward movement of endocardium was identified before or immediately after aortic valve opening in 10 patients (Fig. 2). In 9, the main area involved was the apex, and in 1 the inferior surface. In no case was the anterior wall affected. Studies of regional function indicated that the mean amplitude of outward wall movement during early systole was $2 \cdot 3 \pm 1 \mathrm{~mm}$ (mean \pm 1 standard deviation). The overall excursion of wall movement in affected areas was $9 \pm 1 \mathrm{~mm}$ at a peak velocity of $9.3 \pm 3 \mathrm{~cm} / \mathrm{s}$. These values did not differ significantly from those of $8 \pm 2 \mathrm{~mm}$ and $9 \cdot 4 \pm 3 \mathrm{~cm} / \mathrm{s}$ in normal regions.

\section{ISOVOLUMIC RELAXATION}

Abnormal inward movement of endocardium was present in 10 patients, usually involving the inferior surface (8 patients), or less commonly, the apex (1) or both (1) (Fig. 2). Abnormal outward wall movement (greater than $7 \mathrm{~mm}$ ) occurred in 12 patients, involving the anterior wall in all. Of these, 7 also showed additional inward movement during the same period, involving the inferior surface.

INTERRELATIONS OF CLINICAL FEATURES A number of interrelations was present between abnormal left ventricular wall movement during the 2 isovolumic periods and other clinical features:

(1) The presence of inferior $T$ wave changes on the electrocardiogram was associated with the presence of abnormal wall movement during both isovolumic periods (Fig. 3). This was significant ( $P$ $<0.01$ ). 
Table 2 Relation between isovolumic abnormalities and mitral prolapse

\begin{tabular}{llc}
\hline A) Isovolumic contraction & Mitral prolapse & \\
abnormalities & Present & Absent \\
Present & 8 & 2 \\
Absent & 8 & 27 \\
& & \\
(B) Isovolumic relaxation & Mitral prolapse & \\
abnormalities & Present & Absent \\
Present & 5 & 5 \\
Absent & 11 & 24 \\
\hline
\end{tabular}

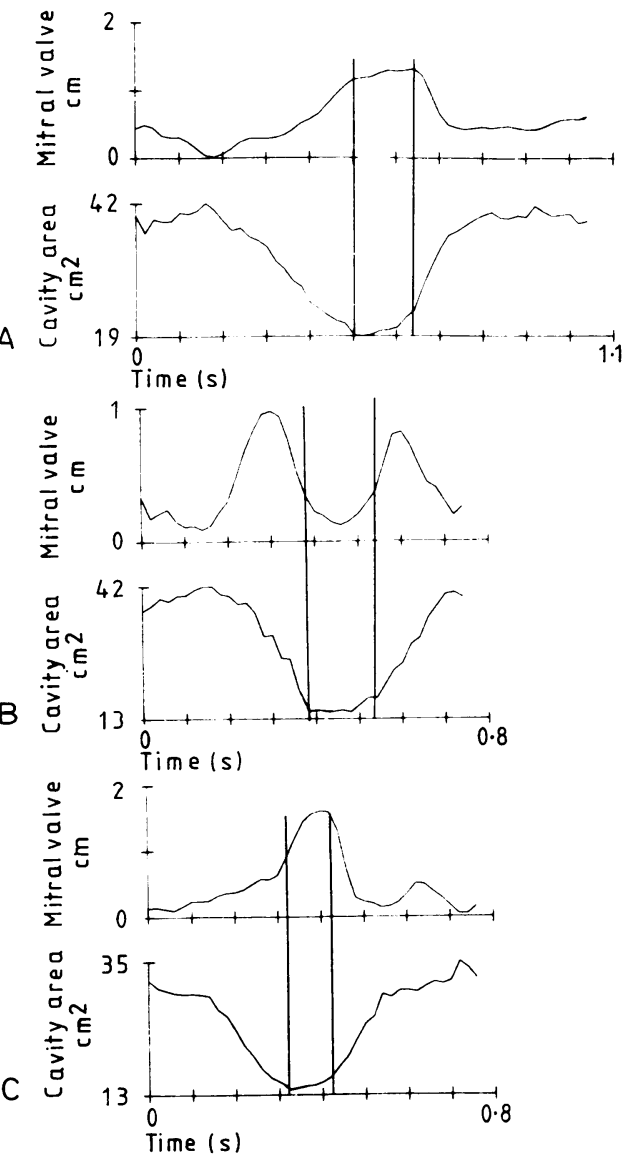

Fig. 4 (A) Selective plot of mitral valve movement in comparison with changes in left ventricular cavity area. The two vertical lines represent the timing of minimum cavity area and mitral valve opening. Upward displacement of the mitral valve trace represents movement of the valve towards the left ventricular cavity. The greater part of valve movement occurs during ejection rather than during isovolumic relaxation. (B) Selective plot of mitral valve movement, showing mid-systolic prolapse of the valve into the left atrial cavity. Layout as Fig. 4A. (C) Selective plot of mitral valve movement, showing delay during ejection, and inward movement occurring mainly during isovolumic relaxation. Layout as Fig. $4 A$.
(2) Abnormalities of isovolumic contraction and relaxation were both present in 8 patients.

(3) Mitral valve prolapse, defined simply as failure of the mitral valve to move inwards in systole, along with the appearance of increased local curvature, determined by direct inspection of angiograms, was present in 16 patients and was associated with the presence of abnormalities of isovolumic contraction (Table 2). In an attempt to analyse this movement in more detail, plots of mitral valve movement were used. In all patients, maximum inward movement of the valve towards the left ventricular cavity occurred at the time of mitral valve opening, followed by outward movement during filling. However, during systole, 3 separate patterns of movement could be defined:

(a) (30 patients). In the majority of patients, the greater part of inward movement occurred during ejection. Between the time of minimum cavity area and mitral valve opening, further inward movement was usually seen, but its amplitude was small (Fig. 4A).

(b) (4 patients). In these patients, inward movement began normally after aortic valve opening, but during mid-ejection there was abrupt outward movement of the valve into the left atrial cavity, which reversed during relaxation. This pattern appeared to represent classical mid-systolic prolapse of the mitral valve (Fig. 4B).

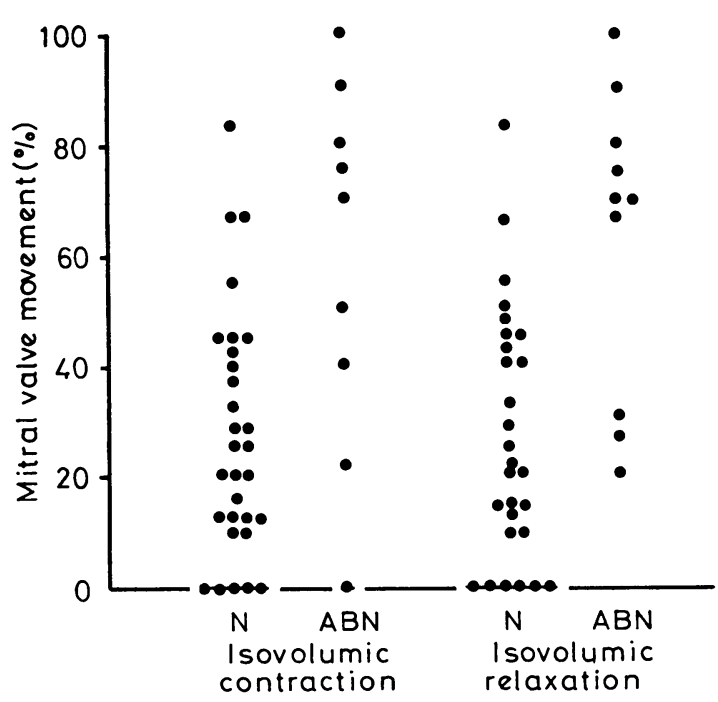

Fig. 5 Relation between mitral valve movement and abnormal left ventricular wall movement during isovolumic contraction and relaxation. Mitral valve movement is expressed in terms of the percentage of the total amplitude over the cardiac cycle occurring during isovolumic relaxation. 
(c) (11 patients). In these patients, the greater part of inward movement of the mitral valve occurred between the times of minimum cavity area and mitral valve opening, that is during isovolumic relaxation. A discontinuity in the rate of inward movement was consistently seen 20 to $40 \mathrm{~ms}$ before the time of minimum cavity area (Fig. 4C).

The relation of these abnormalities of mitral valve movement to those of the ventricular wall is shown in Fig. 5. This shows that abnormal wall movement during either of the two isovolumic periods is associated with the condition of 45 per cent or more of total inward movement of the valve occurring during isovolumic relaxation. There was no relation between abnormal wall movement and mid-systolic prolapse in the 4 patients in whom it was present.

(4) The nature of the chest pain: it was not possible to demonstrate any connection between the nature of the pain and the electrocardiogram, the presence of mitral prolapse, or disturbances of left ventricular wall movement.

\section{Discussion}

In the present study we have suggested that regional differences in timing in wall movement occur in patients who present with chest pain and normal coronary arteries, and in whom standard measures of left ventricular function are normal. Proving this contention is difficult since the ventriculograms of patients of this type are often used as a standard of comparison against which those of patients with more clearly defined pathology are judged. However, other objective abnormalities, including inferior $T$ wave changes and mitral valve prolapse, have been described in similar populations of patients with chest pain and normal coronary arteries (Dwyer et al., 1969; Kemp et al., 1973). In this study, inward movement of the apex or inferior surface of the ventricle during isovolumic relaxation was closely associated with inferior $T$ wave changes on the electrocardiogram, and this relation was specific to this particular abnormality and did not occur with left anterior hemiblock or left bundle-branch block. Though angiographic criteria for the diagnosis of mitral prolapse are not precise, even the qualitative definition used in this study showed a significant association between prolapse and incoordinate wall movement. More detailed analysis indicated that this association was with a specific type of valve motion. The close relation between two independent and objective abnormalities, namely $T$ wave changes and mitral valve prolapse and areas of incoordinate behaviour of the left ventricle, is strong evidence that the detection of such areas is not the result of artefact introduced by the method used to analyse the angiograms, so that they should be considered abnormal.

The disturbance of isovolumic contraction closely resembled that seen in patients with coronary artery disease (Gibson et al., 1978). Outward wall movement started before aortic valve opening, and continued for the first 40 to $60 \mathrm{~ms}$ of ejection. The wall then moved inward, with normal amplitude and velocity, but relaxation in these regions was delayed in 9 out of 11 with respect to other parts of the same ventricle. This type of movement is compatible with the idea that the onset of contraction is delayed in affected areas, but that it proceeds normally thereafter. Abnormalities of isovolumic relaxation were also similar to those seen in coronary artery disease (Gibson et al., 1976), with inward movement of endocardium in one area being associated with outward movement elsewhere to maintain cavity volume constant during the period between aortic valve closure and mitral valve opening. Unlike the distribution seen in coronary artery disease, inward movement during isovolumic relaxation occurred only at the apex and along the inferior surface, so that compensatory movement involved the free wall. These abnormalities of movement are thus very similar to those previously described by a number of authors in patients with mitral valve prolapse accompanied by mid-systolic click and late systolic murmur. These have included delayed inferior relaxation, which may be of such an extent as to cause the development of a two-chambered left ventricle, and also premature outward movement along the anterior wall of the cavity occurring in late systole or early diastole (Grossman et al., 1967; Ehlers et al., 1970; Jeresaty, 1971; Liedtke et al., 1973; Scamperdonis et al., 1973). In these patients, also, coronary arteriography is usually normal in spite of a history of anginal pain and the presence of electrocardiographic abnormalities suggesting local ischaemia (Pocock and Barlow, 1970a).

Several types of mitral valve movement were seen in the present study. One abnormal pattern appeared to correspond with mitral prolapse defined echocardiographically, with abrupt backward movement of the valve into the left atrium during midsystole (Fig. 4B). In our patients, this was not consistently associated with either a mid-systolic click and late systolic murmur or with abnormal wall movement. By contrast, the second type of abnormality, movement downward during isovolumic relaxation rather than during ejection, was frequently associated with abnormal movement at the apex or along the inferior wall. This type of 
movement did not simply reflect that of the base of the heart, since it was not associated with any consistent change in long axis. It is thus unlikely to have been caused by any functional disturbance of longitudinally directed fibres of the ventricular wall, but rather it is the behaviour that would be predicted if there were a delay in the onset of papillary muscle contraction similar to that occurring in the wall. In a further 8 patients, a local increase in mitral valve curvature occurred in the absence of any abnormality of timing. Patients with mitral valve prolapse, therefore, do not seem to be a homogeneous group, and studies of the timing of mitral valve movement may shed further light on this confusing syndrome.

Patients with chest pain and normal coronary arteries may thus present with a variety of interrelated clinical features, for which we offer the following explanation. A primary feature appears to be regional delay in the onset of contraction involving the apex, inferior wall, or papillary muscles, possibly caused by local delay in activation since contraction then proceeds normally in affected areas. The reason for this specificity of site is unknown, but it also occurs in patients with coronary artery disease (Gibson et al., 1978). Since the duration of contraction is normal, delay in the onset of tension is associated with its persistence in affected areas into the period of isovolumic relaxation. Coronary flow, particularly in subendocardial regions (Gregg and Fisher, 1963; Kirk and Honig, 1964), occurs almost exclusively in diastole, so that the combination of persisting tension and a short filling period such as occurs with tachycardia might lead to regional ischaemia. Evidence for myocardial ischaemia occurring during stress testing comes from studies showing lactic acid production (Neill et al., 1968; Bemiller et al., 1973; Kemp et al., 1973; Boudoulas et al., 1974) or the development of perfusion abnormalities (Korhola et al., 1977). Once local ischaemia developed, then relaxation would be further prolonged as occurs experimentally during reperfusion (Tyberg et al., 1974). This would tend to aggravate the interference with coronary flow, leading to the development of angina or even myocardial infarction (Campeau et al., 1968; Greenberg and Dwyer, 1974). The combination of activation delay and local ischaemia might predispose to the development of ventricular arrhythmias, particularly during and immediately after exertion, of the type described by previous authors (Pocock and Barlow, 1970b; Gooch et al., 1972) in patients with mitral valve prolapse.

Although wall motion abnormalities were seen in a proportion of our patients, in 28, or almost two-thirds, left ventriculography was totally normal.
Previous comparison between PA and lateral views (Gibson et al., 1976) makes it unlikely that a significant number of patients with abnormal movement in the isovolumic periods was missed by using single plane angiography. It seems, therefore, that patients with chest pain and normal coronary arteriograms are not a homogeneous population, but that a single subgroup appears to consist of those in whom wall motion abnormalities, mitral prolapse, and $T$ wave changes occur together.

The present results nevertheless have implications for the definition of standards for the assessment of wall movement using ventriculography. Records taken from patients such as we have described are frequently assumed to be normal, though we have given reasons for supposing that in an appreciable number this may not be the case. In the short term, we suggest that patients with mitral prolapse or electrocardiographic abnormalities should be excluded from such studies. In the longer term, one possible approach might be to correlate angiographic studies more closely with noninvasive techniques by which truly normal subjects can be investigated.

The computing equipment used in this study was provided by the DHSS as part of its experimental programme.

\section{References}

Aranda, J. M., Befeler, B., Lazzara, R., Embi, A., and Machado, H. (1975). Mitral prolapse and coronary artery disease. Clinical, hemodynamic and angiographic correlations. Circulation, 52, 245-253.

Bemiller, C. R., Pepine, C. J., and Rogers, A. K. (1973). Long-term observations in patients with angina and normal coronary arteriograms. Circulation, 47, 36-43.

Boudoulas, H., Cobb, T. C., Leighton, R. F., and Wilt, S. M. (1974). Myocardial lactate production in patients with angina-like chest pain and angiographically normal coronary arteries and left ventricle. American fournal of Cardiology, 34, 501-505.

Campeau, L., Lesperance, J., Bourassa, M. G., and Ashekian, P. B. (1968). Myocardial infarction without obstructive disease at coronary arteriography. Canadian Medical Association fournal, 99, 837-843.

Dwyer, E. M., Jr., Wiener, L., and Cox, J. W. (1969). Angina pectoris with normal and abnormal coronary arteriograms: hemodynamic and clinical aspects. American fournal of Cardiology, 23, 639-646.

Ehlers, K. H., Engle, M. A., Levin, A. R., Grossman, H., and Fleming, R. J. (1970). Left ventricular abnormality with late mitral insufficiency and abnormal electrocardiogram. American fournal of Cardiology, 26, 333-340.

Gibson, D. G., Doran, J. H., Traill, T. A., and Brown, D. J. (1978). Abnormal left ventricular wall movement during early systole in patients with angina pectoris. British Heart fournal, 40, 758-766.

Gibson, D. G., Prewitt, T. A., and Brown, D. J. (1976). Analysis of left ventricular wall movement during iso- 
volumic relaxation and its relation to coronary artery disease. British Heart Fournal, 38, 1010-1019.

Gooch, A. S., Vincencio, F., Maranhao, V., and Goldberg, H. (1972). Arrhythmias and left ventricular asynergy in the prolapsing mitral leaflet syndrome. American fournal of Cardiology, 29, 611-620.

Greenberg, H., and Dwyer, E. M., Jr. (1974). Myocardial infarction and ventricular aneurysm in a patient with normal coronary arteries. Chest, 66, 306-308.

Gregg, D. E., and Fisher, L. C. (1963). Blood supply to the heart. In Handbook of Physiology: Circulation, vol. II, p. 1517, ed W. F. Hamilton and P. Down. American Physiological Society, Washington D.C.

Grossman, H., Fleming, R., Engle, M. A., Levin, A. H., and Ehlers, K. H. (1967). Angiography in the apical systolic click syndrome: left ventricular abnormality, mitral insufficiency, late systolic murmur and inversion of $T$ waves. Radiology, 91, 898-904.

Jeresaty, R. M. (1971). Mitral ballooning-a possible mechanism of mitral insufficiency in diseases associated with reduced end-systolic volume of the left ventricle. Chest, 60, 114-115.

Kemp, H. G., Elliott, W. C., and Gorlin, R. (1967). The anginal syndrome with normal coronary arteriography. Transactions of the Association of American Physicians, 80, 59-70.

Kemp, H. G., Vokonas, P. S., and Cohn, P. F. (1973). The angina syndrome associated with normal coronary arteriograms. Report of a six year experience. American fournal of Medicine, 54, 735-742.

Kirk, E. S., and Honig, C. R. (1964). Non-uniform distribution of blood flow and gradients of oxygen tension within the heart. American fournal of Physiology, 207, 661-668.

Korhola, O., Valle, M., Frick, M. H., Wijasalo, M., and Riihimaki, E. (1977). Regional myocardial perfusion abnormalities on Xenon-133 imaging in patients with angina pectoris and normal coronary arteries. American fournal of Cardiology, 39, 355-359.

Liedtke, A. J., Gault, J. H., Leadman, D. M., and Blumenthal,
M. S. (1973). Geometry of left ventricular contraction in the systolic click syndrome. Characterization of a segmental myocardial abnormality. Circulation, 47, 27-35.

Likoff, W., Segal, B. L., and Kasparian, H. (1967). Paradox of normal selective coronary arteriograms in patients considered to have unmistakeable coronary heart disease. New England fournal of Medicine, 276, 1063-1066.

Neill, W. A., Kassebaum, D. G., and Judkins, M. P. (1968). Myocardial hypoxia as the basis for angina pectoris in a patient with normal coronary arteries. New England fournal of Medicine, 279, 789-792.

Pocock, W. A., and Barlow, J. B. (1970a). Etiology and electrocardiographic features of the billowing posterior mitral leaflet syndrome. American fournal of Medicine, 51, 731-737.

Pocock, W. A., and Barlow, J. B. (1970b). Post exercise arrhythmias in the billowing posterior mitral leaflet syndrome. American Heart fournal, 80, 740-745.

Sanderson, J. E., Gibson, D. G., Brown, D. J., and Goodwin, J. F. (1977). Left ventricular filling in hypertrophic cardiomyopathy. British Heart fournal, 39, 661-670.

Scamperdonis, G., Yang, S. S., Maranhao, V., Goldberg, H., and Gooch, A. S. (1973). Left ventricular abnormalities in the prolapsed mitral leaflet syndrome. Circulation, 48, 287297.

Smith, E. R., Fraser, D. B., Purdy, J. W., and Anderson, R. H. (1977). Angiographic diagnosis of mitral valve prolapse: correlation with echocardiography. American Fournal of Cardiology, 40, 165-170.

Tyberg, J. V., Forrester, J. S., Wyatt, M. L., Goldner, S. J., Parmley, W. M., and Swan, M. J. C. (1974). An analysis of segmental ischemic dysfunction utilizing the pressurelength loop. Circulation, 39, 748-754.

Requests for reprints to Dr D. G. Gibson, Cardiac Department, Brompton Hospital, Fulham Road, London SW3 6HP. 